Progress Report Submitted to

Office of Basic Energy Sciences

U.S. Department of Energy

by

G. S. Was

Department of Nuclear Engineering

University of Michigan

Ann Arbor, MI 48109

for

\title{
THE ROLE OF GRAIN BOUNDARY CHEMISTRY AND STRUCTURE IN THE ENVIRONMENTALLY-ASSISTED INTERGRANULAR CRACKING OF NICKEL-BASE ALLOYS
}

Grant \# DE-FG02-85ER45184

\section{DISCLAIMER}

\begin{abstract}
This report was prepared as an account of work sponsored by an agency of the United States Government. Neither the United States Government nor any agency thereof, nor any of their employees, makes any warranty, express or implied, or assumes any legal liability or responsibility for the accuracy, completeness, or usefulness of any information, apparatus, product, or process disclosed, or represents that its use would not infringe privately owned rights. Reference herein to any specific commercial product, process, or service by trade name, trademark, manufacturer, or otherwise does not necessarily constitute or imply its endorsement, recommendation, or favoring by the United States Government or any agency thereof. The views and opinions of authors expressed herein do not necessarily state or reflect those of the United States Government or any agency thereof.
\end{abstract}


Progress during the current grant period (1990-93) focused on five main areas of research: 1) determination of the role of $\mathrm{C}$ and $\mathrm{Cr}$ on the deformation and IG cracking behavior of $\mathrm{Ni}-(5-30) \mathrm{Cr}-9 \mathrm{Fe}, 2)$ determination of the effect of grain boundary misorientation on the IG cracking behavior, 3) construction of an electron backscattering pattern (EBSP) imaging system, 4) determination of the effect of the environment on creep and cracking and 5) characterization of the surface film. Results of the program showed that both $\mathrm{C}$ and $\mathrm{Cr}$ and potent solid solution strengtheners which can reduce the steady state creep rate at $360^{\circ} \mathrm{C}$ by several orders of magnitude. Intergranular cracking of $100 \mu \mathrm{m}$ grain samples of high purity $\mathrm{Ni}-16 \mathrm{Cr}-9 \mathrm{Fe}$ at $360^{\circ} \mathrm{C}$ occurs by the formation of grain boundary voids and their interlinkage, driven by dislocation creep in the matrix. Creep experiments in primary water at $360^{\circ} \mathrm{C}$ and under an applied cathodic potential show that the creep rate is increased by an order of magnitude over that in Ar and the percent IG fracture increases as well. The oxide film composition and thickness is a sensitive function of the $\mathrm{C}$ content, increasing in thickness and $\mathrm{Ni}(\mathrm{OH})_{2}$ content with an increase in $\mathrm{C}$ or with a decrease in $\mathrm{Cr}$ to $5 \mathrm{wt} \%$. Thermomechanical treatments along with electron channeling pattern (ECP) analysis were used to create and index, respectively, samples with enhanced fractions of coincident site lattice boundaries (CSLBs). Constant extension rate tensile (CERT) experiments on samples with a high percentage of CSLBs showed a reduction in the extent of IG cracking as compared with general high angle boundaries, GHABs. However, these experiments were conducted on samples with grain sizes of approximately $300 \mu \mathrm{m}$ in size while commercial material is an order of magnitude smaller. As such, an electron backscattering pattern (EBSP) imaging system has been constructed for use in an environmental scanning electron microscope (ESEM) which can image grains below $5 \mu \mathrm{m}$. The system has been successfully benchmarked against results from ECP analysis. 
COVER PAGE

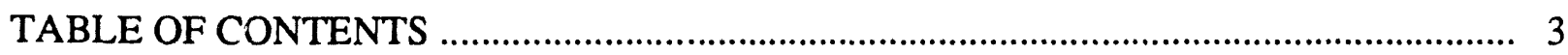

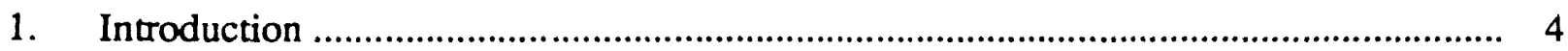

2. Deformation and IG Cracking in Argon........................................................... 4

3. Role of Grain Boundary Misorientation .............................................................. 6

3.1 Misorientation effects on IG cracking …............................................................. 7

3.2 Misorientation effects on creep deformation ..................................................... 8

3.3 Development of an electron backscattering pattern (EBSP) imaging system .......... 9

4. Effect of the Environment on Deformation and Cracking .......................................... 11

5. Oxide Films and Their Relation to Intergranular Cracking ....................................... 13

6. Contribution to Our Current Understanding of the Problem ....................................... 14

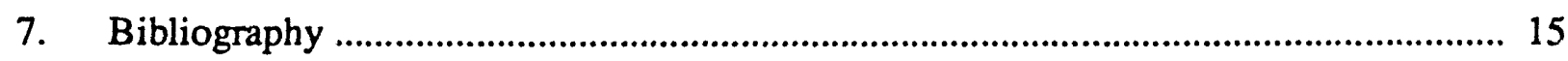

8. Publications From Current Project (1990-93) ...................................................... 16

9. Graduate Student Status and Degrees Awarded f.................................................. 18

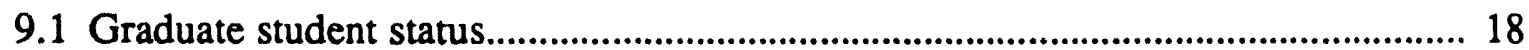

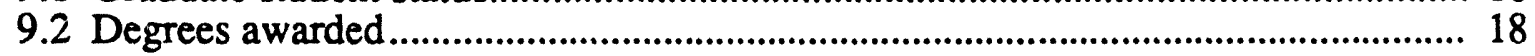

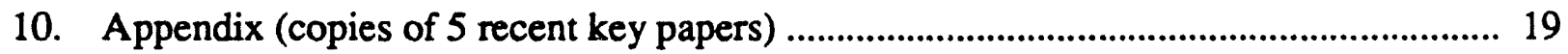




\section{Introduction}

The objective of this program is to determine the mechanism(s) of intergranular cracking of nickel-base alloys in high temperature, high purity water and primary water. Over the last three years, the proposed work, conducted under grant No. DE-FG02-85ER45184, has succeeded in identifying and isolating some important aspects of the deformation and cracking mechanism that were previously not understood or realized. This report summarizes the major findings of the current project over the period 1990-1993. Topics discussed include the effects of $\mathrm{C}$ and $\mathrm{Cr}$ on deformation and IG cracking in an argon environment, the role of grain boundary misorientation on IG cracking, the role of the environment on IG cracking and the characterization and probable role of oxide films on IG cracking.

\section{Deformation and IG Cracking in Argon}

This project has resulted in the determination of the mechanism of grain boundary cracking in high purity $\mathrm{Ni}-\mathrm{Cr}-\mathrm{Fe}$ at $360^{\circ} \mathrm{C}$ in an inert environment. The mechanism is dislocation-controlled creep leading to the nucleation, growth and linkage of grain boundary voids. [1,2] Determination was made by conducting constant extension rate tension (CERT) and constant load tension (CLT) experiments on $\mathrm{Ni}-\mathrm{xCr}-\mathrm{Fe}-\mathrm{yC}$ alloys in $360^{\circ} \mathrm{C}$ argon in order to eliminate the influence of the environment. The presence of grain boundary voids in the cross-sectioned specimens, grain boundary sliding on the side surfaces, and fine dimples on the faceted fracture surface all indicate that creep is acting in conjunction with the imposed plastic deformation from the CERT experiment. Creep is dislocation-controlled and follows either power-law or power-law breakdown behavior in which the stress exponent in the eqn $\alpha \sigma^{\text {n }}$ is between 1 and 5 , or greater than 5 , respectively.

The link between the intergranular failure mode and the deformation mode of creep in CERT experiments is understood by considering the evolution of the grain boundary morphology with increasing stress or strain. At lower strains (corresponding to low stress), creep leads to the nucleation of grain boundary voids which begin to grow. At intermediate strains, the growing voids link up into larger voids and form cavities. At higher strains, cavity interlinkage forces ductile overload in the remainder of the cross section, producing intergranular facets covered with creep-induced voids on the order of 1-2 microns in size, Fig. 1. Failure is based on a type of 'damage accumulation' process in which the damage accumulates at a more rapid rate at higher loads where creep rates 


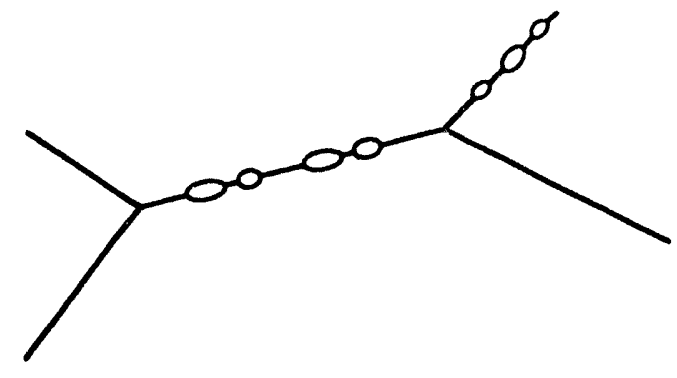

low strain

(away from necked region)

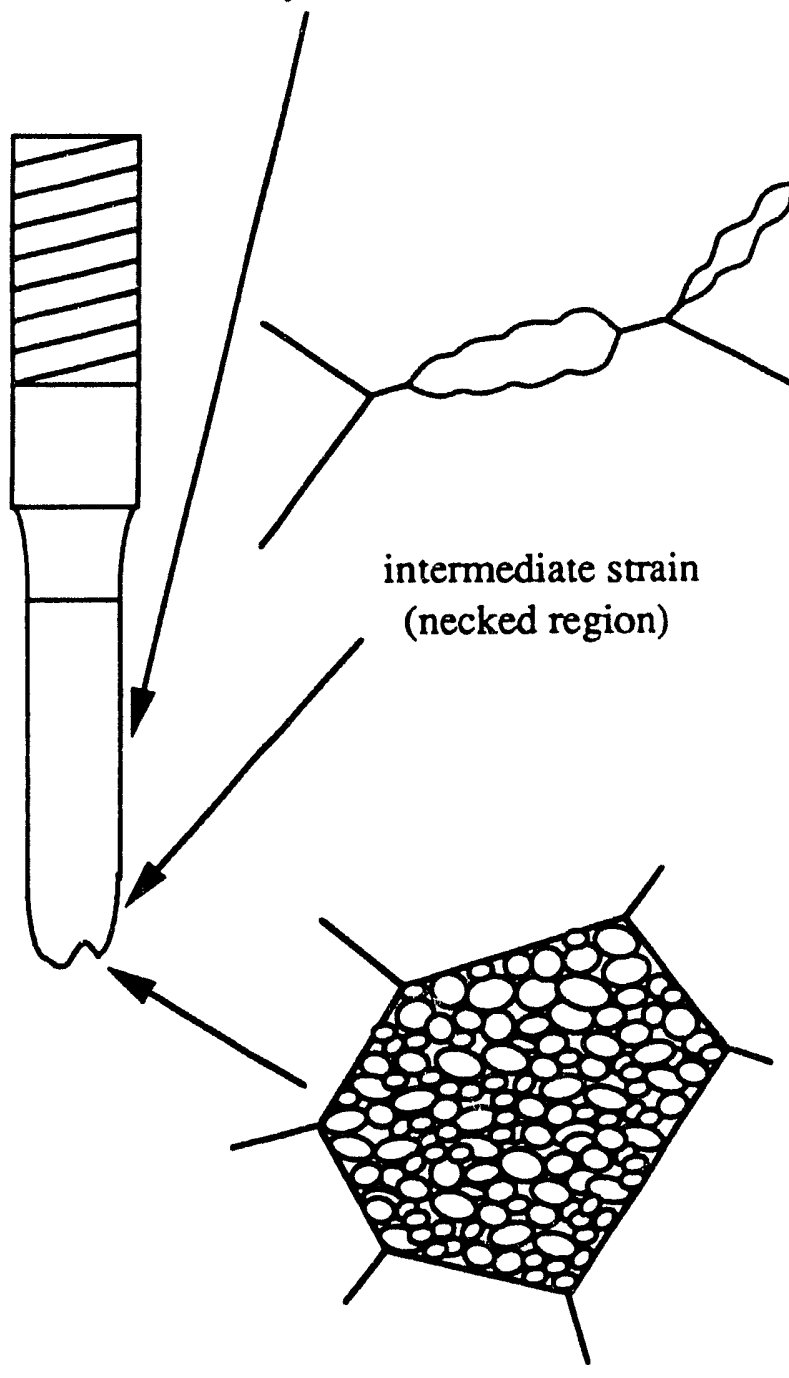

high strain

(fracture surface)
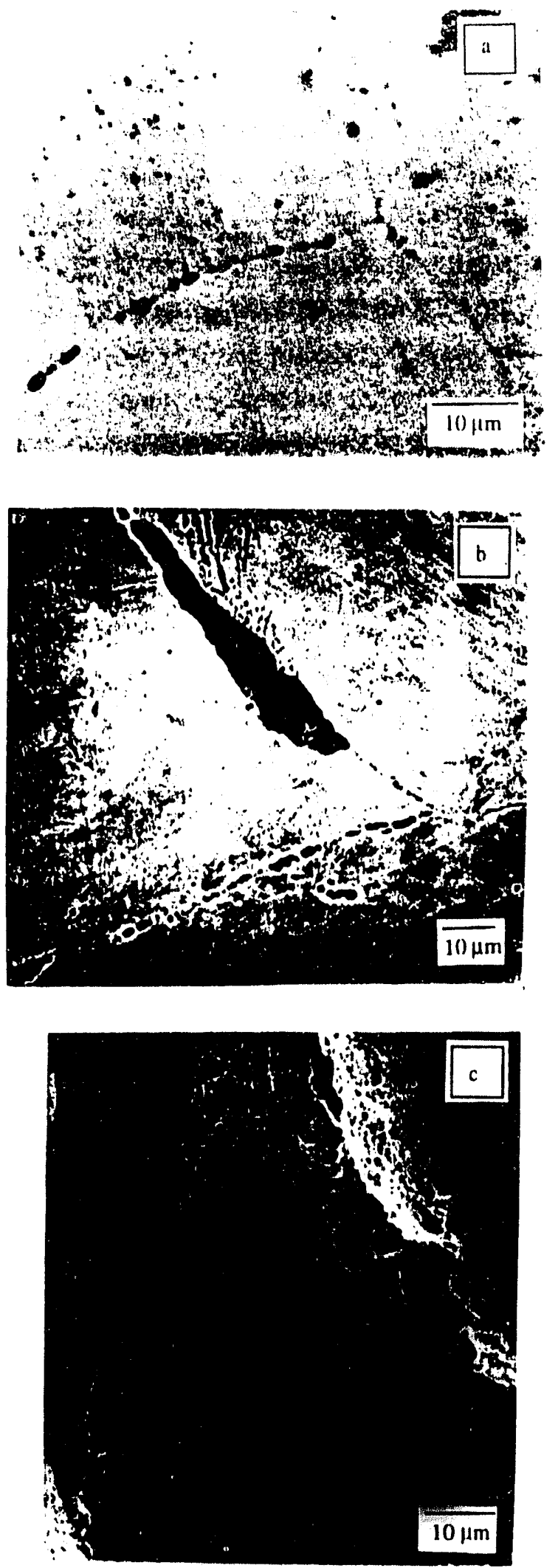

Figure 1. Evolution of grain boundary damage accumulation process due to creep in a CERT experiment on the UHP6 alloy at $360^{\circ} \mathrm{C}$ showing the (a) presence of grain boundary voids at low strain, away from neck (b) void link up at intermediate strain in the necked region, and (c) complete failure in the highest strain region at the fracture surface. 
are higher. The longer the time spent at these higher loads (i.e. a slower strain rate), the larger is the accumulated creep strain resulting in more extensive grain boundary cavity formation and more IG cracking.

The additions of chromium and carbon to nickel-base alloys improve their resistance to IG cracking in argon at $360^{\circ} \mathrm{C}$. Carbon is an extremely potent solid solution strengthener, resulting in a decrease in the creep rate by over 4 orders of magnitude as the carbon level in increased from 20 to 300 wppm. [3] The very potent effect of small concentrations of carbon on creep behavior indicates that dislocation-carbon interaction is occurring during creep with the probable result that originally mobile dislocations are being pinned, as evidenced by serrated yielding during deformation, Fig 2a. Chromium also strongly affects creep by a solid solution strengthening mechanism, Fig. 2b. [2] The creep rate (in stop-load experiments) is reduced by several orders of magnitude as the chromium content is increased from 5 to $30 \mathrm{wt} \%$. Hence, both $\mathrm{C}$ and $\mathrm{Cr}$ influence the amount of IG cracking through their influence on the creep rate of the alloy.

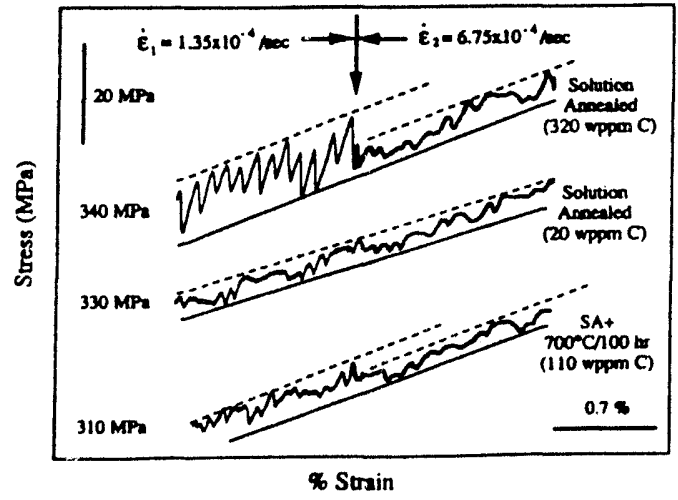

Fig. 2a. Strain rate dependence of serration behavior as a function of carbon in solution at $400^{\circ} \mathrm{C}$.

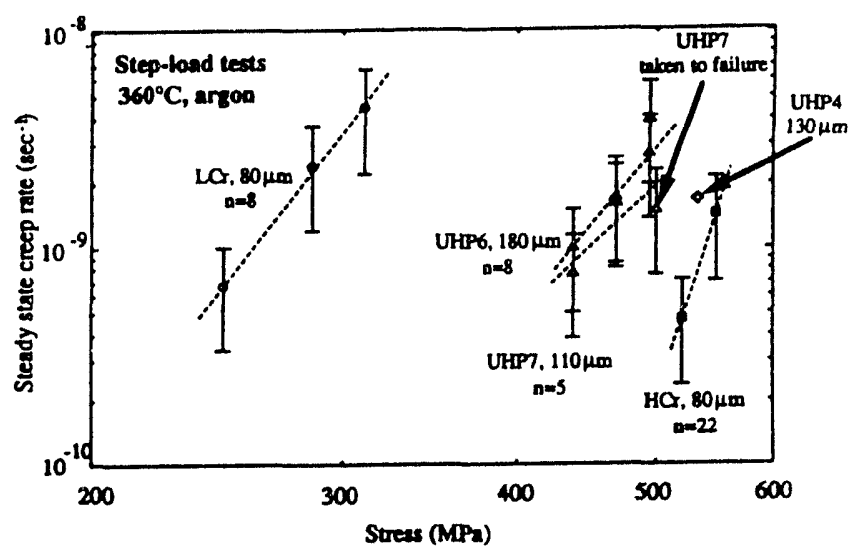

Fig. 2b. Summary of step-load test results showing the effect of chromium on the steady state creep rate of $\mathrm{Ni}-\mathrm{xCr}-9 \mathrm{Fe}-\mathrm{C}$ alloys in argon at $360^{\circ} \mathrm{C}$.

\section{Role of Grain Boundary Misorientation}

Our recent work on this topic has revolved about three areas; 1) the effect of grain boundary misorientation on IG cracking in high purity water, 2) the determination of the effect of grain boundary character distribution on creep deformation, and 2) development of an electron backscattering pattern imaging system. 


\subsection{Misorientation effects on IG cracking}

The effect of grain boundary misorientation on the intergranular cracking behavior of pure $\mathrm{Ni}-16 \mathrm{Cr}-9 \mathrm{Fe}$ was assessed by determining if low angle boundaries (LABs) or coincident site lattice boundaries (CSLBs) are more resistant to cracking than general high angle boundaries (GHABs) in argon and water. [4] Cracking susceptibility of boundary types was determined using CERT experiments in $360^{\circ} \mathrm{C}$ argon and deaerated water. IG cracking susceptibility was determined using two measures: the \% of characterized grain boundaries that cracked, and the average cracked boundary fraction. Samples were either in the annealed condition (typically $4 \%$ LAB, $18 \%$ CSLB, $78 \%$ GHAB) or the CSLB-enhanced condition (4\% LAB, 36\% CSLB, 60\% GHAB).

Cracked boundary fractions for CSLB-enhanced samples tested in either environment ranged from 0.01 to 0.08 , while those for annealed samples ranged from 0.07 to 0.10 , indicating that samples with increased proportions of CSLBs are more crack resistant. No LABs cracked in either environment. In annealed samples, the proportion of CSLBs that cracked in water was $6.7 \%$ compared to $1.5 \%$ in argon; the proportion of GHABs that cracked in water was $9.3 \%$ compared to $6.6 \%$ for argon. Thus, CSLBs are more crack resistant than GHABs in either environment, and both are more crack resistant in argon than in water. The higher amounts of cracking and the higher CSLB cracking susceptibility in high purity water indicate the presence of an environmental effect on cracking behavior. Results are summarized in table 1 and Fig. $3 a$.

Table 1. Numbers of Characterized and Cracked Boundaries by Type for Annealed and CSLB-Enhanced Samples Tested in High Purity Water and Argon.

\begin{tabular}{|c|c|c|c|c|c|c|c|c|}
\hline & \multicolumn{4}{|c|}{ high purity water } & \multicolumn{4}{|c|}{ argon } \\
\hline & $\begin{array}{l}\# 0 \\
\text { typ }\end{array}$ & $\begin{array}{l}\% \text { of } \\
\text { total }\end{array}$ & $\begin{array}{c}\# \\
\text { cracked }\end{array}$ & $\begin{array}{l}\text { \%o of } \\
\text { type }\end{array}$ & $\begin{array}{l}\text { \# of } \\
\text { type }\end{array}$ & $\begin{array}{l}\% \text { of } \\
\text { total }\end{array}$ & $\begin{array}{c}\# \\
\text { cracked }\end{array}$ & $\begin{array}{l}\% \text { of } \\
\text { type }\end{array}$ \\
\hline & \multicolumn{8}{|c|}{ annealed samples } \\
\hline $\begin{array}{l}\text { CSLBS } \\
\text { LABs } \\
\text { GHABS }\end{array}$ & $\begin{array}{r}119 \\
29 \\
526 \\
\end{array}$ & $\begin{array}{r}18 \% \\
4 \% \\
78 \% \\
\end{array}$ & $\begin{array}{r}8 \\
0 \\
49 \\
\end{array}$ & $\begin{array}{c}6.7 \% \\
0 \\
9.3 \%\end{array}$ & $\begin{array}{r}67 \\
35 \\
396 \\
\end{array}$ & $\begin{array}{r}13 \% \\
7 \% \\
80 \% \\
\end{array}$ & $\begin{array}{r}1 \\
0 \\
26 \\
\end{array}$ & $\begin{array}{c}1.5 \% \\
0 \\
6.6 \% \\
\end{array}$ \\
\hline \multirow[t]{2}{*}{ Total } & 674 & & 57 & $8.5 \%$ & 498 & & 27 & $5.4 \%$ \\
\hline & \multicolumn{8}{|c|}{ CSLB-enhanced samples } \\
\hline $\begin{array}{l}\text { CSLBs } \\
\text { LABs } \\
\text { GHABS }\end{array}$ & $\begin{array}{r}228 \\
33 \\
356\end{array}$ & $\begin{array}{r}37 \% \\
5 \% \\
58 \%\end{array}$ & $\begin{array}{r}4 \\
0 \\
19\end{array}$ & $\begin{array}{c}1.8 \% \\
0 \\
5.3 \%\end{array}$ & $\begin{array}{r}119 \\
22 \\
225\end{array}$ & $\begin{array}{r}33 \% \\
6 \% \\
61 \%\end{array}$ & $\begin{array}{l}2 \\
0 \\
1\end{array}$ & $\begin{array}{c}1.7 \% \\
0 \\
0.4 \%\end{array}$ \\
\hline Total & 617 & & 23 & $3.7 \%$ & 366 & & 3 & $0.8 \%$ \\
\hline
\end{tabular}

1. Percentage of total charactereized boundaries.

2. Percentage of boundary type that is cracked. 
The beneficial effect of LABs and CSLBs is likely due to the ability of these boundaries to induce slip in neighboring grains by either transmitting or absorbing and reemitting lattice dislocations, thereby reducing grain boundary stresses and the propensity for crack initiation. The results indicate that control of grain boundary proportions can improve the intergranular stress corrosion cracking susceptibility of pure $\mathrm{Ni}-16 \mathrm{Cr}-9 \mathrm{Fe}$.

\subsection{Misorientation effects on creep deformation}

Results from constant load tests of annealed (SA) and CSLB-enhanced samples with a comparable grain size indicate that the creep behavior of this alloy can be significantly influenced by altering the grain boundary character distribution. Using a grain size of $330 \mu \mathrm{m}$, two constant load tests on annealed samples reached the tertiary stage at 165 and $115 \mathrm{~h}$ at total strains of $1.8 \%$ and $1.35 \%$, respectively, Fig. 3b. A marked difference in creep resistance of the CSLB-enhanced sample as compared to the annealed samples was observed. The CSLB-enhanced sample did not reach the tertiary stage until after $250 \mathrm{~h}$ at a total creep strain of $0.8 \%$. However, the most striking difference was in the distribution of creep strain between the creep regimes. In the SA samples, primary creep accounted for $80 \%$ of the total strain as compared to $<40 \%$ in the CSLB-enhanced sample. This latter sample spent the bulk of its life in the secondary regime whereas steady state creep

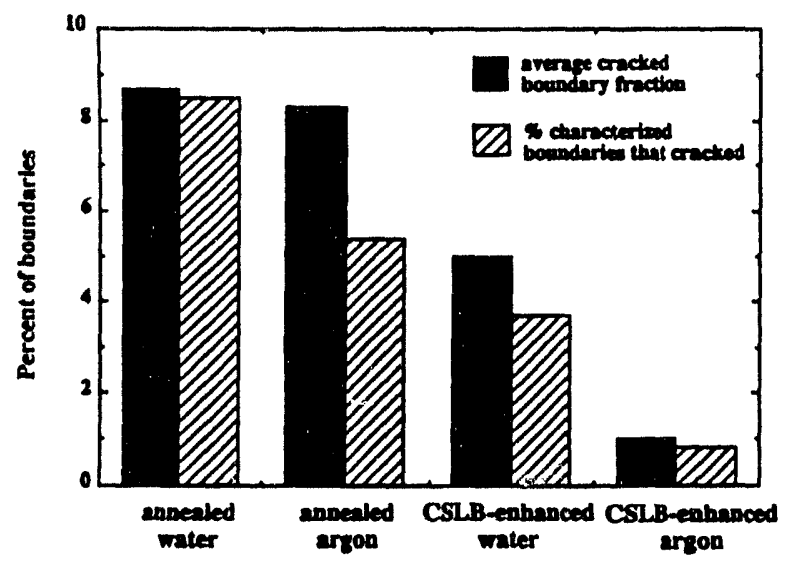

Fig. 3a. Comparison between cracked boundary fractions and the percentages of characterized boundaries that cracked.

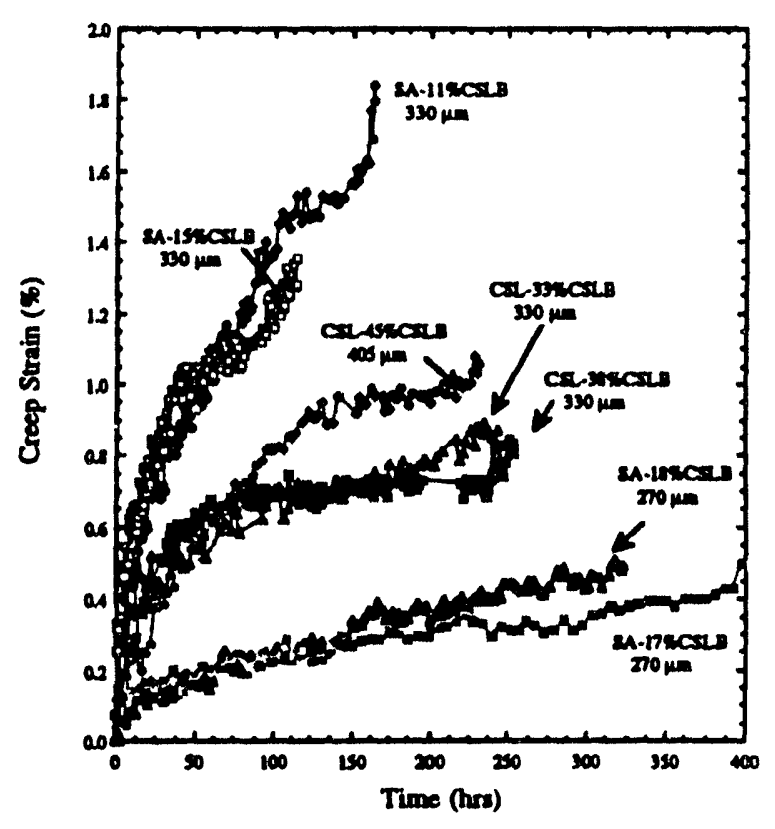

Fig. 3b. Constant load creep curves of SA/CSL Ni-16Cr-9Fe alloys at $300 \mathrm{MPa}$ in $360^{\circ} \mathrm{C}$ argon. 
was reached only momentarily in the SA samples. It is interesting to note that a CSLBenhanced sample with a $405 \mu \mathrm{m}$ grain size also exhibited superior creep resistance, implying that the influence of grain size may play a secondary role in creep behavior compared to grain boundary character distribution.

Scanning electron microscopy revealed that most of the cracks in the annealed samples are wedge type whereas the CSLB-enhanced samples do not show any preferential crack types. The wedge geometry was shown by Chang and Grant [5] to be due to grain boundary sliding which is known to be an important source of creep deformation. Watanabe [6] demonstrated that the amount of sliding strongly depends on the type and misorientation of grain boundaries and it occurs more easily in GHABs. Kokawa et al. [7] reported that GHABs exhibited more sliding than CSLBs. Since grain boundary sliding has been shown to be proportional to the amount of total creep strain [8], a sample with more CSLBs would be expected to exhibit less total strain. Thus, the observed difference in the creep behavior between annealed samples and a CSLBenhanced sample may be interpreted in terms of the effect of grain boundary misorientation on the rate of grain boundary sliding.

\subsection{Development of an electron backscattering pattern (EBSP) imaging system}

A second project involves the development of an electron backscattering pattern (EBSP) imaging system for use in an environmental scanning electron microscope (ESEM). This system was developed to allow us to address grain boundary character distributions in small grain samples typical of commercial material $(15-25 \mu \mathrm{m})$ as compared to the restriction of the electron channeling pattern method which requires nominal grain sizes $>200 \mu \mathrm{m}$. [9] To facilitate EBSP imaging, the standard specimen stage in the ESEM has been replaced with a special specimen mount that holds the sample at an angle of $19.4^{\circ}$ to the electron beam. EBSPs are formed when the electron beam is focused on a crystal or grain as a stationary probe; as a result, the spatial resolution of the technique is only limited by the electron beam size $(\approx 1 \mu \mathrm{m})$. In this technique, EBSPs are imaged directly on a phosphor screen mounted on a stainless steel tube that is attached to the leaded glass viewing port in the side of the microscope's sample chamber. EBSPs are recorded by digitizing the image from a Dage-MTI CCD-72 TV camera coupled with a Nikon $60 \mathrm{~mm}$ macro lens and a $1.4 \mathrm{x}$ Nikon teleconvertor and sent to a Scion LG-3 frame capture board installed in an Apple Macintosh IIci personal computer. The patter quality is improved significantly by incorporating a small program to subtract the background level semi-automatically. In order to generate accurate 
orientation information, the stage of the microscope is controlled by a small program written in the National Instrument LabVIEW2 environment to assure the same working height as those from the calibration specimen while the sample is being translated. Online analysis of EBSPs is achieved by incorporating software into the public domain image processing program, Image 1.45. Thus orientations can be calculated while EBSPs are being imaged. Fig. 4 a illustrates a diagram of the system constructed for this work.

In order to evaluate differences in results obtained wiin the EBSP and SACP techniques, grain boundaries in an ultra high purity $\mathrm{Ni}-16 \mathrm{Cr}-9 \mathrm{Fe}$ alloy were characterized with both techniques. Due to the limitation in spatial resolution in the SACP technique, a sample of the alloy was prepared by solution annealing at $1200^{\circ} \mathrm{C} / 1.5 \mathrm{hr}$. to produce a mean grain size of $320 \mu \mathrm{m}$. [10] Prior to pattern imaging, the sample surface was mapped out with backscattered electron images and 70 grain boundaries were assigned. Fig. 4b shows the distribution of grain boundary misorientation angle determined by SACPs and EBSPs. The distribution shows excellent agreement between the techniques.

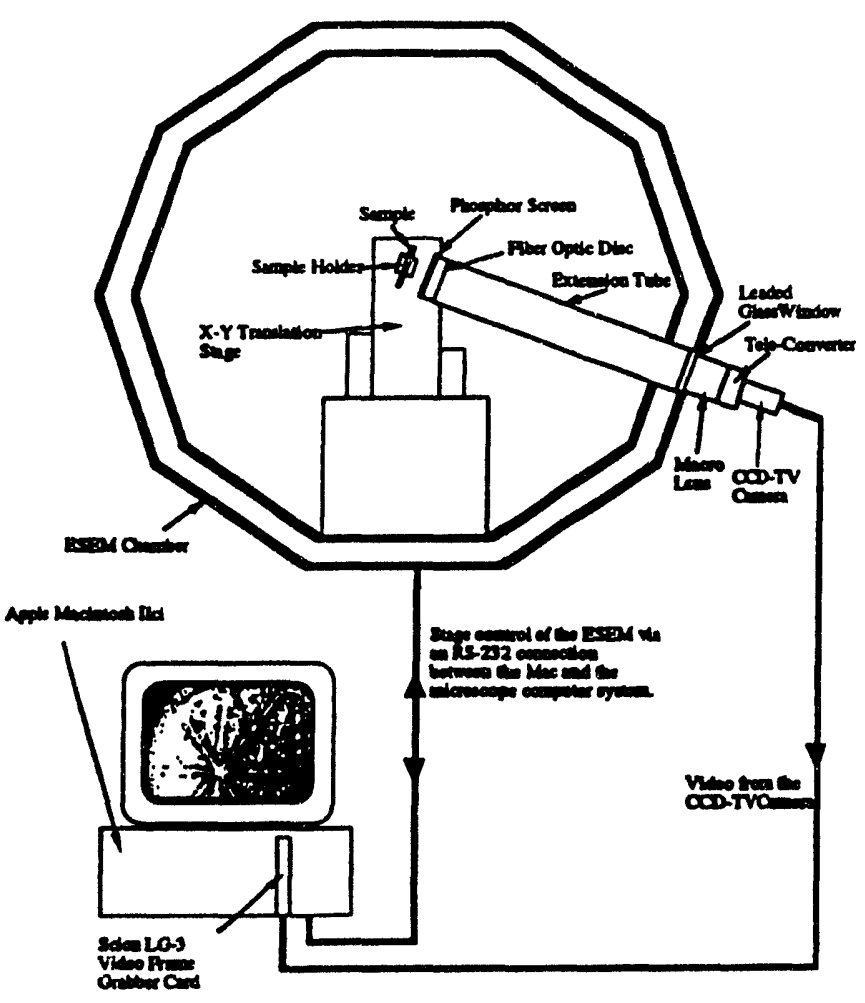

Fig. 4a. Schematic diagram of the EBSP camera on the Electroscan ESEM.

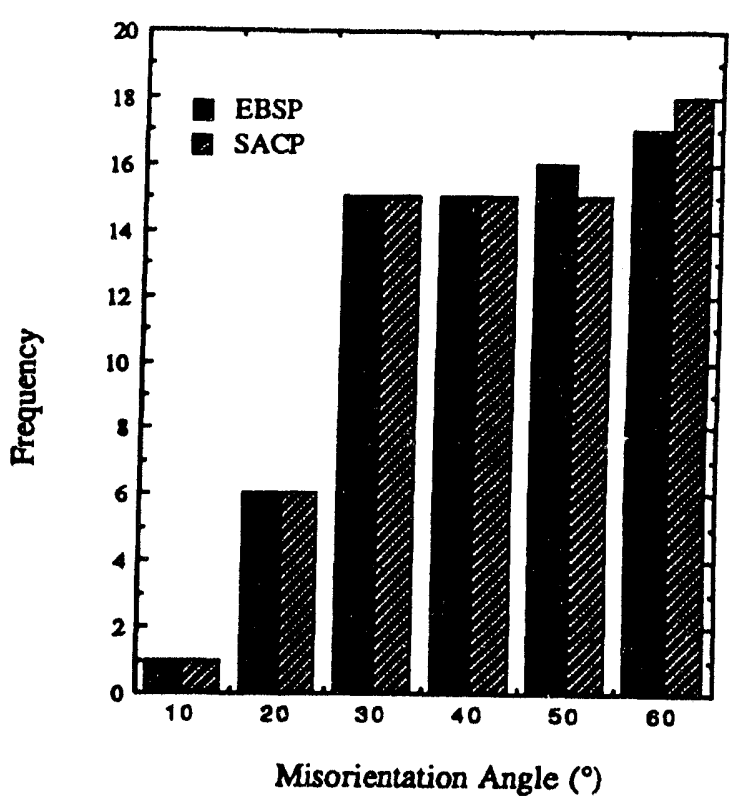

Fig. 4b. Comparison of grain boundary misorientation distribution of SA $\mathrm{Ni}-16 \mathrm{Cr}-9 \mathrm{Fe}$ after $1.5 \mathrm{~h}$ at $1200^{\circ} \mathrm{C}$ using SCAP and EBSP techniques. 
It was found that the average difference in grain boundary misorientation angle between the two techniques is only $0.98^{\circ}$. The difference in grain boundary misorientation angle may be due to a larger distortion introduced by gnomonic projection in EBSPs which is a direct result of the angular view of diffraction space of EBSPs that extends over $90^{\circ}$ whereas it covers no more than $20^{\circ}$ in SACPs. A major difference between the two techniques used in the present work was found to be the time required to completely characterize 70 grain boundaries. Owing to the capability to perform on-line analysis of EBSPs, the EBSP technique required only half the time as the SACP technique.

\section{Effect of the Environment on Deformation and Cracking}

The most recent accomplishment has been the determination that hydrogen is the likely cause of the increase in intergranular cracking in high temperature water. [11] This conclusion is based on both CERT and CLT experiments conducted in high purity water and primary water at controlled potentials. One of the most significant observations is the large increase in creep rate in primary water over that in argon. In primary water, the creep rate of ultra-high purity $\mathrm{Ni}-16 \mathrm{Cr}-\mathrm{Fe}$ at $360^{\circ} \mathrm{C}$ and $500 \mathrm{MPa}$ at a potential of -1150 $\mathrm{mV}$ SHE is an order of magnitude greater than that in water, Fig. 5a. The time to failure is reduced by a factor of three and the \% IG fracture is increased by $50 \%$. A detailed examination of both the side surfaces and the cross-section of the samples revealed that while dislocation plasticity accounted for $84 \%$ of the strain in the sample tested in argon, the percentage increased to $96 \%$ of the strain in water. This was due to a drop in the fractional strain due to grain boundary sliding and grain boundary cavitation. Although dislocation plasticity is the dominant deformation mechanism in both cases, grain boundary sliding and cavitation play an even smaller role during creep in water.

Constant extension rate tensile (CERT) tests of alloys with varying levels of $\mathrm{Cr}$ and $\mathrm{C}$ revealed a consistent increase in IG cracking percentage on the fracture surface in high purity water as compared with argon. However, two observations should be noted. First, the amount of cracking in both environments decreases with increasing $\mathrm{Cr}$ or $\mathrm{C}$ level. Second, the difference between the amount of cracking in the two environments decreases as the amount of $\mathrm{Cr}$ or $\mathrm{C}$ increases. For example, although the difference in \%IG cracking in water and argon is $42 \%$ vs. $27 \%$, respectively, for the $\mathrm{LCr}(5 \mathrm{wt} \% \mathrm{Cr}$, low $\mathrm{C}$ ) alloy, the difference drops to $2 \%$ for the high $\mathrm{Cr}$ alloy $(30 \mathrm{wt} \%$ ) and zero for the 300 wppm $C$ alloys. CERT results in primary water with an applied potential are even

more significant as they show that a cathodic potential ( $230 \mathrm{mV}$ below OCP) results in 
the greatest amount of IG cracking with progressively less IG cracking at OCP and less still at anodic potentials, $\sim 250 \mathrm{mV}$ above OCP, Fig. $5 \mathrm{~b}$. Both sets of results point toward hydrogen as the likely species accelerating the creep rate and enhancing IG fracture.

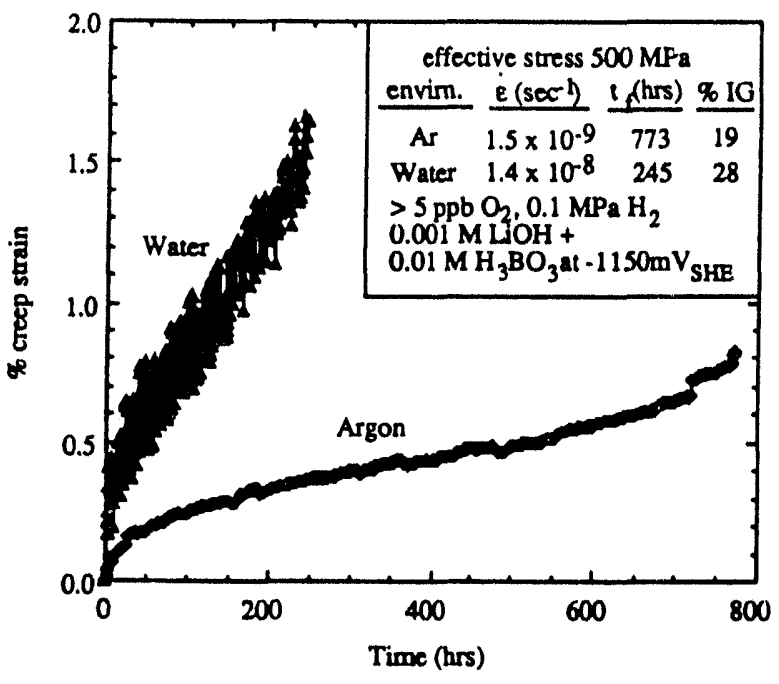

Fig. 5a. CLT test results of the UHP7 alloy at an effective stress of $500 \mathrm{MPa}$ in $\mathrm{Ar}$ and deaerated, hydrogenated, $0.001 \mathrm{M} \mathrm{LiOH}+$ $0.01 \mathrm{M} \mathrm{H}_{3} \mathrm{BO}_{3}$ water at $-1150 \mathrm{mV}$ SHE at $360^{\circ} \mathrm{C}$ and an initial strain rate of $3 \times 10^{-7} \mathrm{~s}^{-1}$.

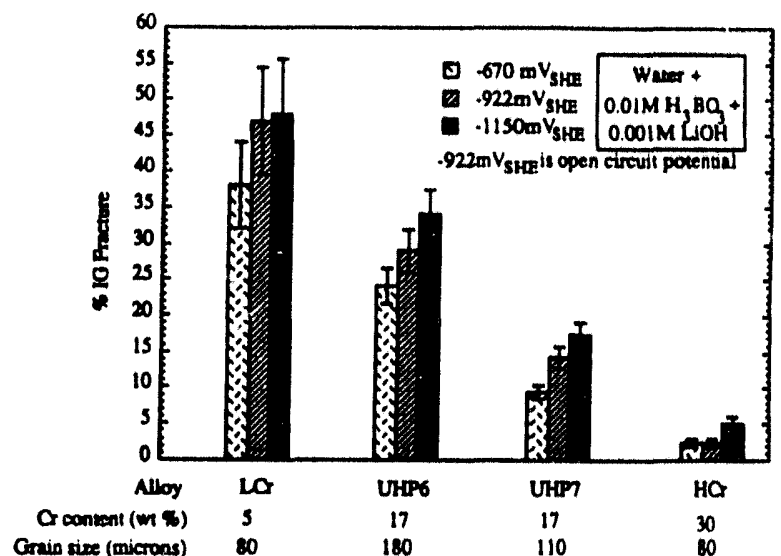

Fig. 5b. CERT test results as a function of chromium, grain size, environment and potential in $0.001 \mathrm{M} \mathrm{LiOH}+0.01 \mathrm{M} \mathrm{H}_{3} \mathrm{BO}_{3}$ at $360^{\circ} \mathrm{C}$ at an initial strain rate of $3 \times 10^{-7} \mathrm{~s}^{-1}$.

The relationship between the deformation mode of dislocation-controlled creep and the fracture mode of IG cracking is believed to be as follows. Time dependent deformation in the matrix causes a strain at the grain boundary that must be accommodated, usually by the processes of cavitation and sliding. Without these processes, the strain must be accounted for by another manner such as slip transfer across the grain boundary. Fracture in argon indicates that grain boundaries are inherently weak and prone to failure. Therefore, accommodation of the matrix deformation occurs by the formation of grain boundary cracks. It follows that as the amount of creep damage increases, the amount of IG cracking should also increase. This is verified by the results which show that the amount of IG cracking increases as the strain rate in a CERT test decreases. However, it still needs to be determined whether the amount of matrix creep deformation or the rate of time dependent deformation is responsible for the IG cracking behavior. Most likely it is a combination of the two. For the UHP7 alloy crept at $360^{\circ} \mathrm{C}$ and $500 \mathrm{MPa}$, it was shown that the amount of side surface IG cracking increased by a 
factor of 3 as the matrix strain doubled and the creep rate increased by a factor of 10 in water over that of argon, preventing any clear conclusion about the effect of the rate and amount of strain. It may be that the strain rate is more important in the water environment than argon, where a synergistic effect between hydrogen and dislocation motion may occur. Further experimentation is necessary to separate the effects of creep strain rate and total creep strain on the IG cracking behavior of these alloys at $360^{\circ} \mathrm{C}$.

\section{Oxide Films and Their Relation to Intergranular Cracking}

Since the surface film has been implicated in several models of intergranular stress corrosion cracking (IGSCC) of nickel-base alloys, this study was initiated to provide a foundation from which to determine the possible link between the nature of the surface film and IG cracking susceptibility. The influence of chromium, carbon anc yttrium on the nature of the surface film formed on nickel-base alloys was investigated after 100 hours of exposure in high purity, deaerated, hydrogenated water at $360^{\circ} \mathrm{C}$. The chemical composition of an ultra-high purity (UHP) alloy of $\mathrm{Ni}-17 \mathrm{Cr}-9 \mathrm{Fe}-0.0030 \mathrm{C}$ was altered by varying the $\mathrm{Cr}$ content, doping with $\mathrm{C}$, or ion implanting $\mathrm{Y}$. X-ray photoelectron spectrosccpy and scanning transmission electron microscopy provided information on the chemical composition, structure, morphology and thickness of the surface film. Increasing the chromium content of a Ni-xCr-9Fe-low $\mathrm{C}$ alloy from 5 to $17 \mathrm{wt} \%$ dramatically changes the surface film from predominantly $\mathrm{Ni}(\mathrm{OH})_{2}$ to $\mathrm{Cr}_{2} \mathrm{O}_{3}$. An additional increase in $\mathrm{Cr}$ from 17 to $30 \mathrm{wt} \%$ does not significantly alter the type, distribution or thickness of the oxide phases formed. This suggests that there is a critical chromium concentration that controls the formation of $\mathrm{Cr}_{2} \mathrm{O}_{3}$ after 100 hours of exposure to high purity, deaerated, hydrogenated water at $360^{\circ} \mathrm{C}$. The presence of $\mathrm{Cr}_{2} \mathrm{O}_{3}$ in these alloys is attributed to the high affinity of $\mathrm{Cr}$ for oxygen, and the increased stability of $\mathrm{Cr}_{2} \mathrm{O}_{3}$ over many other oxides in reducing environments. The addition of $300 \mathrm{wppm}$ carbon to a Ni-17Cr-9Fe- $0.0030 \mathrm{C}$ alloy increases the film thickness while promoting the formation of $\mathrm{Ni}(\mathrm{OH})_{2}$, possibly by an increase in the diffusion of $\mathrm{Ni}$ or by an enhancement of the surface activity of the $\mathrm{Ni}$ atoms. The addition of $300 \mathrm{wppm}$ carbon to a Ni-30Cr-9Fe- $0.0020 \mathrm{C}$ alloy increases the film thickness without changing $\mathrm{Cr}_{2} \mathrm{O}_{3}$ as the dominant surface species. Ytrium implantation to $2.4 \mathrm{at} . \%$ at a depth of $70 \mathrm{~nm}$ in $\mathrm{Ni}-17 \mathrm{Cr}-9 \mathrm{Fe}-0.0030$ and $0.030 \mathrm{C}$ alloys produces a similar film thickness and similar composition profiles containing slightly more $\mathrm{Ni}(\mathrm{OH})_{2}$ than $\mathrm{Cr}_{2} \mathrm{O}_{3}$. Ytrium is known for forming $\mathrm{Y}_{2} \mathrm{O}_{3}$ which most likely promotes the formation of $\mathrm{Cr}_{2} \mathrm{O}_{3}$ by acting as nucleation sites for the similarly structured chromia. 
In primary water, the film thickness remains unchanged but the nickel content in the film is substantially reduced at $-1150 \mathrm{mV}$ SHE. This is expected based on the potential-pH diagram since this potential is about $200 \mathrm{mV}$ below the $\mathrm{Ni} / \mathrm{NiO}$ line. Nevertheless, the decrease in $\mathrm{Ni}(\mathrm{OH})_{2}$, or the corresponding increase in the $\mathrm{Cr}_{2} \mathrm{O}_{3}$ fraction of the film correlates inversely with SCC cracking susceptibility. The most likely explanation for this effect is that it is not the protectiveness of the film which is critical but the generation and absorption of hydrogen which is controlling. It also shows that the major role of $\mathrm{Cr}$ in the alloy is in reducing the creep rate rather than in forming a more protective film.

\section{Contribution to Our Current Understanding of the Problem}

It is important to consider these results in the context of the collective understanding of the problem of IG cracking in high temperature water. These results ha" - added substantially to this body of knowledge in several respects. The mechanism of IG cracking in ultra-high purity $\mathrm{Ni}-16 \mathrm{Cr}-9 \mathrm{Fe}$ is now well understood to be due to grain boundary void formation, growth and link-up. For the first time, the roles of $\mathrm{Cr}$ and $\mathrm{C}$ (in solution) on deformation and cracking have been cleariy determined. Also, the first definitive set of data on the role of the environment in the deformation behavior of the alloy has been acquired. These results implicate hydrogen as the likely species causing an enhancement in dislocation plasticity in the matrix. The results are also the first to show a substantial increase in steady state creep rate in water over that in an inert environment. The studies on grain boundary misorientation show that CSLBs are more resistant to cracking in high purity water than GHABs. Also, the creep deformation is considerably different for a CSLB-enhanced microstructure over that of a microstructure consisting of a random distribution of grain boundary misorientations. Finally, we have shown how $\mathrm{Cr}$ and $\mathrm{C}$ affect the formation of the oxide film and that the film composition and thickness does not seem to control the observed IG cracking.

The results of this program have shed considerable light on the mechanism of cracking. They have also prompted important new and better focused questions regarding the cracking mechanism. These include, is hydrogen really the culprit? If so, how does the increased dislocation plasticity translate into an increased propensity for IG cracking? Knowing the role of $\mathrm{C}$ in solution, what is the role of $\mathrm{C}$ in the form of carbides and how can these be separated? Is the deformation and cracking response of small grain material similar to that for large grain material? What is the mechanism by which carbon in solution or CSLBs change affect grain boundary deformation to make the boundaries 
more resistant to IG cracking? A program designed to answer these questions is described in the accompanying renewal proposal.

7. Bibliography

1. Alloy 600 Experts Meeting, Electric Power Research Institute, Warrenton, VA, April, 1993.

2. T. M. Angeliu and G. S. Was, submitted to Metall. Trans. A.

3. J. K. Sung, J. W. Jones and G. S. Was, Metall. Trans,, 23A (1992) 1033-1037.

4. D. Crawford and G. S. Was, Metall. Trans. A 23A (1992) 1195-1206.

5. H. C. Chang and N. J. Grant, AIME Trans. 206 (1956) 544; Joumal of Metals, May, 1956.

6. T. Watanabe, Metall. Trans. $14 \mathrm{~A}$ (1983) 531.

7. H. Kokawa, T. Watanabe and S. Karashima, Phil. Mag, A. 44, No. 6, (1981) 1239.

8. H. Conrad, Mechanical Behavior of Materials at Elevated Temperatures, J. E. Dom, ed., McGraw-Hill, 1961, p. 218.

9. J. F. Mansfield, V. Thaveeprungsriporn and G. S. Was, "Design and Construction of an Electron Backscattering Pattern Camera for the Environmental Scanning Electron Microscope," Scanning '93, Orlando, FL, April, 1993.

10. D. C. Crawford and G. S. Was, L. Electron Micoscopy Techn. 19 (1991) 345.

11. G. S. Was, T. M. Angeliu and J. K. Sung, presented at "Alloy 600 Experts Meeting", Electric Power Research Insititute, Warrenton, VA, April, 1993. 
8. Publications From Current Project (1990-1993)

Journal Articles

1. V. Thaveeprungsriporn, J. Mansfield and G. S. Was, "Development of an Electroil Backscattering Pattern (EBSP) Imaging System for an Environmental Scanning Electron Microscope," submitted to Ultramicroscopy.

2. T. Angeliu and G. S. Was, "Environmental Effects of Intergranular Cracking Behavior of $\mathrm{Ni}-\mathrm{Cr}-\mathrm{Fe}$ Alloys at High Temperature," submitted to Metall. Trans.

3. T. Angeliu and G. S. Was, "Creep and Intergranular Cracking of $\mathrm{Ni}-\mathrm{Cr}-\mathrm{Fe}$ Alloys in Argon at $360^{\circ} \mathrm{C}$," submitted to Metall. Trans.

4. T. Angeliu and G. S. Was, "The Effect of Chromium, Carbon and Yttrium on the Oxidation of Nickel-Base Alloys in High Temperature Water," L.Electrochem. Soc. in press.

5. J. K. Sung, J. Kock, T. M. Angeliu and G. S. Was, "Effects of Grain Boundary Chemistry on Intergranular Cracking of $\mathrm{Ni}-16 \mathrm{Cr}-9 \mathrm{Fe}$ in $50 \% \mathrm{NaOH}$ at $140^{\circ} \mathrm{C}$," Metall. Trans. A, 23A (1992) 2887.

6. G. S. Was, J. K. Sung and T. M. Angeliu, "Effects of Grain Boundary Chemistry on Intergranular Cracking of Ni-16Cr-9Fe in High Temperature Water," Metall. Trans. A, 23A (1992) 3343.

7. D. Crawford and G. S. Was, "The Effect of Grain Boundary Misorientation on the Intergranular Cracking Behavior of Ni-16Cr-9Fe in Argon Atmosphere and High Purity Water at $360^{\circ} \mathrm{C}$," Metall. Trans. A 23A (1992) 1195-1206.

8. J. K. Sung, J. W. Jones and G. S. Was, "Effect of Carbon on the Low Temperature Creep Behavior of Ni-16Cr-9Fe," Metall. Trans. A. 23A (1992) 1033-1038.

9. J. K. Sung and G. S. Was, "Intergranular Cracking of Ni-16Cr-9Fe Alloys in High Temperature High Purity Water," Corrosion, 47 No. 11 (1991) 824-834.

10. D. Crawford and G. S. Was, "Grain Boundary Character Distributions in Ni-Cr-Fe using Electron Channeling Patterns: Methodology and Results" L. Electron Microscopy Technique, 19 (1991) 345-360.

11. T. Angeliu and G. S. Was, "Grain Boundary Chemistry and Precipitation in Controlled Purity Alloy 690," Metall. Trans., 21 A (1990) 2097-2107.

12. G. S. Was, "Grain Boundary Chemistry and Intergranular Fracture in Austenitic Nickel-Base Alloys - A Review," Corrosion, 46, No. 4 (1990) 319-330.

\section{Conferences}

1. J. F. Mansfield, V. Thaveeprungsriporn and G. S. Was, "Design and Construction of an Electron Backscattering Pattern Camera for the Environmental Scanning Electron Microscope," Scanning '93, Orlando, FL, April, 1993. 
2. T. M. Angeliu and G. S. Was, "Corrosion-Deformation Interactions in the IG Cracking of Nickel-Base Alloys in High Temperature Water," Research in Progress Symposium, Corrosion '93, National Association of Corrosion Engineers, New Orleans, March, 1993.

3. G. S. Was, T. M. Angeliu and J. K. Sung, "Deformation and Intergranular Cracking Behavior of Ni-Cr-Fe Alloys at High Temperature," Proc. EPRI Workshop on Mechanisms of Cracking in Alloy 600, Warrenton, VA, April, 1993, in press.

4. G. S. Was, "Intergranular Cracking of Nickel-Base Alloys," Proc. EPRI Workshop on Directions for Research on Corrosion Assisted Cracking Initiation, Arlington Heights, IL, September, 1992, p c.1.3.

5. T. Angeliu, J. Hertzberg, V. Thaveeprungsriporn and G. S. Was, "The Effect of Chromium and Carbon on the Intergranular Cracking of Ni-Cr-Fe-C Alloys at $360^{\circ} \mathrm{C}$, "Proc. Microstructures and Mechanical Properties of Aging Materials, Fall 1992 TMS Meeting, Chicago, Nov. 1992.

6. G. S. Was, "Microchemical and Microstructural Effects on Stress Corrosion Cracking of Nickel-Base Alloys," in Proc. Parkin's Symposium on Fundamental Aspects of Stress Corrosion Cracking, The Minerals, Metals and Materials Society of AIME, S.M. Bruemmer, E. I. Meletis, R. H. Jones, W. W. Gerbrich, F. P. Ford and R. W. Staehle, eds., (1992) pp. 371-388.

7. D. C. Crawford and G. S. Was, "The Effect of Grain Boundary Misorientation on the Intergranular Cracking Behavior of Ni-16Cr-9Fe in High Purity Water and Argon at $360^{\circ} \mathrm{C}$," Proc. Fifth International Symposium on Environmental Degradation of Material in Nuclear Power Systems - - Water Reactors, American Nuclear Society, (1992) 488-494.

8. G. S. Was, J. K. Sung and T. M. Angeliu, "Effects of Grain Boundary Chemistry on the IGSCC Behavior of Ni-16Cr-9Fe in $360^{\circ} \mathrm{C}$ Water and 50\% NaOH," Proc. Eifth International Symposium on Environmental Degradation of Material in Nuclear Power Systems -- Water Reactors, American Nuclear Society, (1992) 475-481.

9. T. M. Angeliu and G. S. Was, "The Roles of Chromium and Carbon on the Oxidation Behavior of Nickel-Base Alloys in High Temperature Water," Corrosion 91, National Association of Corrosion Engineers.

10. T. M. Angeliu and G. S. Was, "Grain Boundary Chemistry and Precipitation in Controlled Purity Alloy 690," in Proc. Environmental Degradation of Materials in Nuclear Power Systems - Water Reactors, G. J. Theus and D. Cubicciotti, NACE, Houston, 1991, 564-578.

11. G. S. Was and J. K. Sung, "The Role of Grain Boundary Chemistry in Pure Water Intergranular Stress Corrosion Cracking of Ni-16Cr-9Fe Alloys," in Proc. Environmental Degradation of Materials in Nuclear Power Systems - Water Reactors, G. J. Theus and D. Cubicciotti, NACE, Houston, 1991, pp.635-637.

12. J. K. Sung and G. S. Was, "Intergranular Cracking of Ni-16Cr-9Fe Alloys in High Temperature High Purity Water," Corrosion 90, National Association of Corrosion Engineers, Houston, paper \#519, 1990. 
9. Graduate Student Status and Degrees Awarded

\subsection{Graduate student status}

Two graduate students are being supported on this program and are pursuing advanced degrees. One student (Visit) has achieved candidacy and the other (Jason) has passed the written exam and is preparing for the oral exam.

Visit Thaveeprungsriporn is working on grain boundary misorientation effects on cracking. He has recently completed the construction and benchmarking of the electron backscattering pattern (EBSP) imaging system on the environmental scanning electron microscope (ESEM). He is now engaged in developing thermomechanical treatments to control the CSLB fraction in fine grain samples of $\mathrm{Ni}-16 \mathrm{Cr}-9 \mathrm{Fe}$. He will conduct experiments designed to determine the role of grain boundary misorientation in deformation and IG cracking. I expect him to complete his PhD. by August, 1995.

Jason Hertzberg is working on determining the role of carbon in solution and as carbides in deformation and IG cracking of $\mathrm{Ni}-16 \mathrm{Cr}-9 \mathrm{Fe}$. He has recently passed his written candidacy exam and is preparing for his oral exam this summer. He should achieve candidacy by December, 1993. I expect that he will finish his thesis by January, 1996.

\subsection{Degrees Awarded}

During the last three years, three PhDs were awarded to students who were supported on this project.

Jin K. Sung: "Effects of Grain Boundary Chemistry on the Ir tergranular Cracking Behavior of Ni-16Cr-9Fe in High Temperature, High Purity Water and 50\% $\mathrm{NaOH}, " \mathrm{PhD}$ thesis, University of Michigan, 1990.

Douglas C. Crawford: "The Effect of Grain Boundary Misorientation on the Intergranular Cracking Behavior of Ni-16Cr-9Fe in $360^{\circ} \mathrm{C}$ Argon and High Purity Water," PhD thesis, University of Michigan, 1991.

Thomas M. Angeliu: "The Intergranular Cracking Behavior of Ni-Cr-Fe-low C Alloys at $360^{\circ} \mathrm{C}$," $\mathrm{PhD}$ thesis, University of Michigan, 1993. 
10. Appendix (copies of 5 recent key papers)

- T. Angeliu and G. S. Was, "Creep and Intergranular Cracking of Ni-Cr-Fe Alloys in Argon at $360^{\circ} \mathrm{C}$," submitted to Metall. Trans.

- T. Angeliu and G. S. Was, "The Effect of Chromium, Carbon and Yttrium on the Oxidation of Nickel-Base Alloys in High Temperature Water," L.Electrochem. Soc. in press.

- J. K. Sung, J. Kock, T. M. Angeliu and G. S. Was, "Effects of Grain Boundary Chemistry on Intergranular Cracking of $\mathrm{Ni}-16 \mathrm{Cr}-9 \mathrm{Fe}$ in $50 \% \mathrm{NaOH}$ at $140^{\circ} \mathrm{C}$," Metall. Trans, A, 23A (1992) 2887.

- G. S. Was, J. K. Sung and T. M. Angeliu, "Effects of Grain Boundary Chemistry on Intergranular Cracking of $\mathrm{Ni}-16 \mathrm{Cr}-9 \mathrm{Fe}$ in High Temperature Water," Metall. Trans. A, 23 A (1992) 3343.

- D. Crawford and C. S. Was, "The Effect of Grain Boundary Misorientation on the Intergranular Cracking Behavior of $\mathrm{Ni}-16 \mathrm{Cr}-9 \mathrm{Fe}$ in Aigon Atmosphere and High Purity Water at $360^{\circ} \mathrm{C}$," Metall. Trans. A 23A (1992) 1195-1206. 

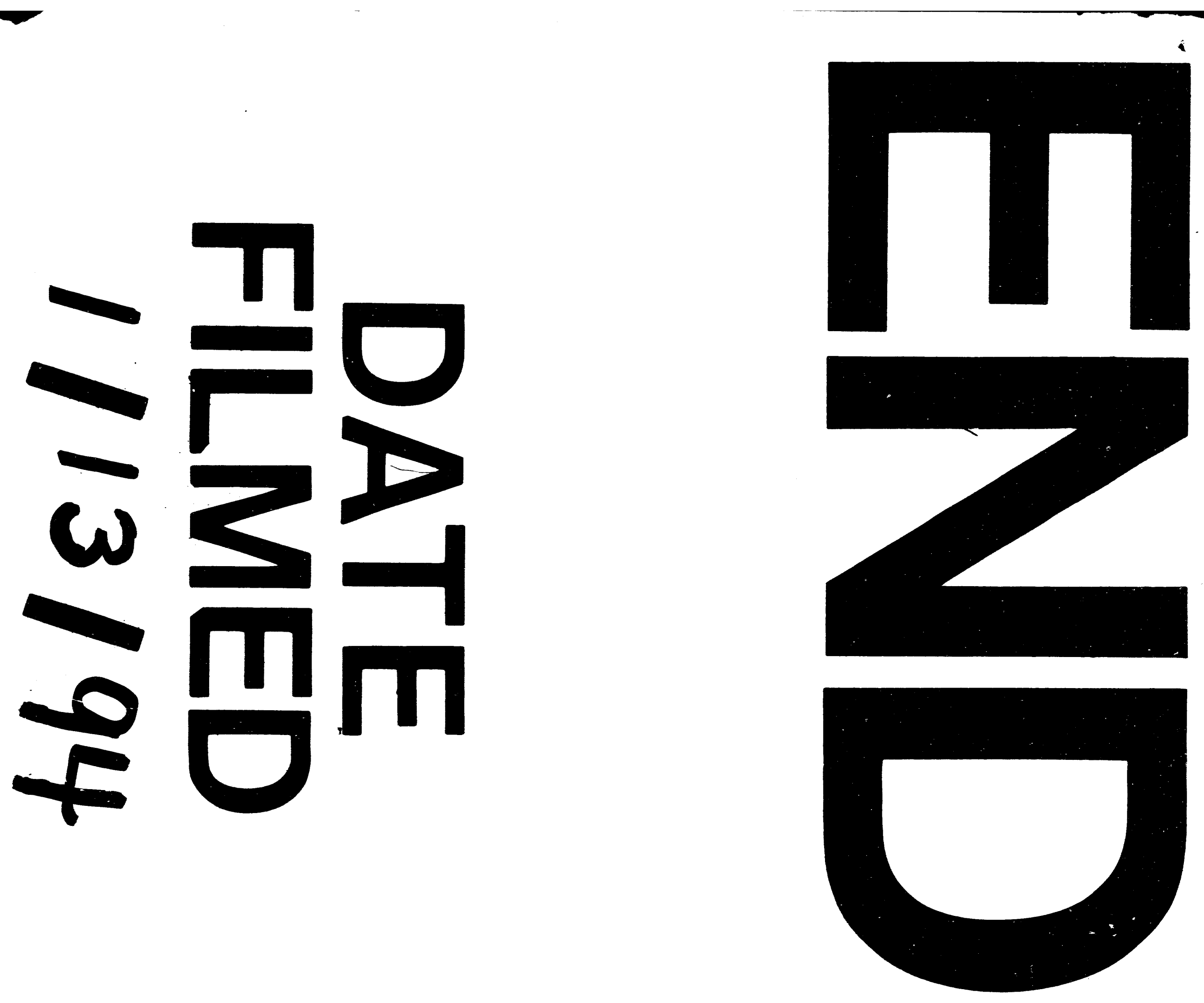
